\title{
Gardnerella vaginalis and anaerobic bacteria in genital disease
}

\author{
SOAD TABAQCHALI, M WILKS, AND R N THIN \\ From the Departments of Medical Microbiology, and Genital Medicine, St Bartholomew's Hospital, \\ London
}

SUMMARY In a study of Gardnerella vaginalis and anaerobic bacteria in non-specific vaginitis (NSV) and other genital diseases 89 patients attending a genital medicine clinic had vaginal samples examined for conventional pathogens and for quantitative analysis of $G$ vaginalis and aerobic and anaerobic bacterial flora. The overall incidence of $G$ vaginalis was $20 \%$; $G$ vaginalis (mean concentration $7 \cdot 0 \log _{10} / \mathrm{g}$ of secretion) occurred predominantly in patients with NSV (57\%) but also in sexual contacts of non-specific urethritis (NSU) $(37 \cdot 5 \%)$ and in patients with other conditions $(11 \cdot 8 \%)$. $G$ vaginalis is therefore a relatively common isolate in patients with vaginal discharge.

The concentration of aerobic and anaerobic bacteria ranged from $4 \cdot 9-11 \cdot 0 \log _{10} / \mathrm{g}$ of secretion with an anaerobe-to-aerobe ratio of $10: 1$. Anaerobic bacteria, particularly anaerobic Grampositive cocci (mean concentrations $7 \cdot 7 \log _{10} / \mathrm{g}$ ), were present in patients with NSV and in association with $G$ vaginalis, but they also occurred in other clinical groups and with other pathogens, particularly Trichomonas vaginalis. Anaerobic bacteria may therefore play an important role in the pathogenesis of vaginal infections.

\section{Introduction}

Vaginal discharge is a common and distressing complaint in clinical practice. Known pathogens, such as Candida spp and Trichomonas vaginalis, are isolated from some patients, and of these the majority have so-called non-specific vaginitis (NSV). Rational treatment and management of patients with NSV has often been unsatisfactory because of the uncertainty surrounding its aetiology. Recently, there has been a resurgence of interest in the possible association of Gardnerella vaginalis with NSV. ${ }^{1-3}$

Since 1955, when Gardner and Dukes ${ }^{4}$ first suggested that a small Gram-negative bacillus, Haemophilus vaginalis (now reclassified as Gardnerella vaginalis ${ }^{5}$ ) was associated with these symptoms, the pathogenic and taxonomic status of this organism has been the subject of much controversy. Some reports confirmed the original observations of a close association whereas others disputed any correlation between $G$ vaginalis and $\mathrm{NSV}^{6}$ and even suggested that $G$ vaginalis is part of the normal vaginal flora. ${ }^{7}$

Address for reprints: Dr S Tabaqchali, Department of Medical Microbiology, St Bartholomew's Hospital, London ECl

Accepted for publication 23 September 1982
Furthermore, the isolation of anaerobic bacteria in association with $G$ vaginalis ${ }^{13}$ and the response of patients to treatment with metronidazole ${ }^{1-3}$ led to the suggestion that anaerobes may also play an important role in this syndrome, whereas other workers failed to isolate any anaerobes. ${ }^{2}$ To determine whether $G$ vaginalis alone or in combination with anaerobes are the cause of NSV it is important to establish their occurrence not only in patients with $\mathrm{NSV}^{13}$ but also in those with other genital diseases. We therefore carried out a quantitative and qualitative study of the aerobic and anaerobic bacterial flora of vaginal secretions obtained from patients attending a genital medicine clinic from whom a variety of pathogens were isolated including $G$ vaginalis.

\section{Patients and methods}

Eighty-nine patients attending the department of genital medicine, St Bartholomew's Hospital, London, had vaginal samples investigated routinely for the presence of known and potential pathogens, namely gonococci, Candida, trichomonads, ureaplasmas, and chlamydia, and also had vaginal samples collected for qualitative and quantitative analysis of the aerobic and anaerobic bacterial flora 
using a method described by us in detail. ${ }^{8}$ Women who had taken antimicrobials in the preceding month were excluded from the study.

Specimens were processed in an anaerobic chamber using prereduced enriched culture media. ${ }^{8}$ The minimum concentration of organisms that could be detected was $3.0 \log _{10} \mathrm{cfu} / \mathrm{g}$ of secretion. Identification of organisms was carried out according to the methods of Cowan and Steel ${ }^{9}$ for aerobic bacteria and Holdeman, Cato and Moore ${ }^{10}$ for anaerobic bacteria. For technical reasons the results obtained for the chlamydia and ureaplasma cultures were invalid and will be excluded from this report.

$G$ vaginalis was isolated on Brucella agar supplemented with $10 \%$ horse blood and differentiated from other oxidase negative and catalase-negative Gram-variable organisms by the production of a small $\beta$-haemolytic zone in human blood agar, by the hydrolysis of hippurate, and by the fermentation of galactose, starch, and maltose. ${ }^{11} 12$

Patients were grouped according to their disease syndrome and pathogens isolated-for example, gonococcal disease (GC), Trichomonas vaginalis (TV), Candida, non-specific vaginitis (NSV), nonspecific genital infection (NSGI), non-specific urethritis contacts (NSU contact), and non-venereal disease (non-VD).

\section{DEFINITIONS OF DIAGNOSES}

In this study NSV was defined as the presence of an abnormal amount of vaginal discharge of unspecified colour, with or without inflammation of the vaginal mucosa (as judged by a single clinician), and existing in the absence of other pathogens and any contact with known sexually transmitted disease (STD). In addition, these patients did not have a gross excess of leucocytes on Gram-stained cervical smears or inflammatory changes affecting the epithelial cells on the Papanicolaou-stained cervical smears.

NSGI was defined as the presence of a gross excess of leucocytes in Gram-stained cervical smears, inflammatory changes affecting the epithelial cells in Papanicolaou cervical smears, and the absence of GC, TV, Candida, and any contact with a patient with any STD.

Patients classified as non-VD had no excess of vaginal discharge, no GC or Candida, none of the inflammatory changes noted in patients with NSGI, and no known contact with any STD.

\section{Results}

A summary of the incidence and the mean and range of concentration of the organisms isolated in the different clinical conditions is shown in table I.
Aerobic bacteria were isolated from all 89 patients and anaerobic bacteria from all but four patients. The concentration of organisms in the different clinical conditions ranged from 4.9-11.0 $\log _{10} \mathrm{cfu} / \mathrm{g}$ of vaginal secretions. Anaerobic bacteria outnumbered aerobes by approximately $10: 1$ except in the contacts of NSU and the non-VD group, in whom the anaerobes were present at lower counts (table I). $G$ vaginalis was isolated from eight of 14 $(57 \%)$ patients with NSV and in six of $16(37 \cdot 5 \%)$ contacts of NSU (mean concentrations $7 \cdot 0$ and $7 \cdot 4$ $\log _{10} \mathrm{cfu} / \mathrm{g}$ respectively), $G$ vaginalis was rarely isolated in cases of GC, TV, candidiasis, NSGI, and non-VD, where the overall incidence was $11 \cdot 8 \%$.

Anaerobic Gram-positive cocci were a common component of the vaginal flora in all conditions with high isolation rates from patients with NSGI $(71 \%)$ and NSV (64\%), contacts of NSU $(62 \cdot 5 \%)$, and patients with TV (53\%). Bacteroides species were isolated from 27 patients and were not associated with any particular group (table I). The different species and the distribution of anaerobic Grampositive cocci and bacteroides are shown in tables II and III. Anaerobic Gram-negative cocci were much

TABLE II Strains of peptococci and peptostreptococci spp isolated from 47 patients

\begin{tabular}{lll}
\hline Species & $\begin{array}{l}\text { No of strains } \\
\text { isolated }\end{array}$ & $\begin{array}{l}\text { Mean concentration } \\
(\log 10 \text { cfu/g secretion) }\end{array}$ \\
\hline Pc magnus & 11 & $7 \cdot 9$ \\
Pc asaccharolyticus & 13 & $8 \cdot 3$ \\
Pc prevottii & 2 & $7 \cdot 8$ \\
Pc variabilis & 3 & $5 \cdot 9$ \\
Ps micros & 7 & $7 \cdot 8$ \\
Ps productus & 3 & $6 \cdot 0$ \\
Ps parvulus & 2 & $7 \cdot 0$ \\
Ps anaerobius & 8 & $8 \cdot 6$ \\
Unidentified & 9 & $8 \cdot 2$ \\
Total & 58 & \\
\hline
\end{tabular}

TABLE III Strains of bacteroides spp isolated from 27 patients

\begin{tabular}{|c|c|c|}
\hline Species & $\begin{array}{l}\text { No of struins } \\
\text { isolated }\end{array}$ & $\begin{array}{l}\text { Mean concentration } \\
\left(\log _{10} \mathrm{cfu} / \mathrm{g} \text { secretion) }\right.\end{array}$ \\
\hline $\begin{array}{l}B \text { fragilis } \\
B \text { thetaiotaomicron } \\
B \text { vulgatus } \\
B \text { melaninogenicus } \\
\text { ss melaninogenicus } \\
\text { ss intermedius } \\
B \text { bivius } \\
B \text { disiens } \\
B \text { assacharolyticus } \\
\text { Bacteroides spp } \\
\text { (unidentified) }\end{array}$ & $\begin{array}{r}3 \\
1 \\
1 \\
6 \\
4 \\
11 \\
3 \\
4\end{array}$ & $\begin{array}{l}7 \cdot 6 \\
8 \cdot 3 \\
7 \cdot 9 \\
6 \cdot 4 \\
7 \cdot 6 \\
7 \cdot 3 \\
7 \cdot 2 \\
7 \cdot 9 \\
7 \cdot 1\end{array}$ \\
\hline
\end{tabular}


less commonly isolated and showed no correlation with any particular clinical condition. Anaerobic Gram-positive rods, especially lactobacilli, were also common. Escherichia coli, which was the only coliform organism isolated, was found in four patients, three of whom had NSV. A more detailed analysis of the bacterial findings will be reported elsewhere.

The association of anaerobic cocci with $G$ vaginalis in the patients in the different groups is shown in the figure. The combination of both organisms in high concentration ( $>5.0 \log _{10} \mathrm{cfu} / \mathrm{g}$ ) of vaginal secretions occurred predominantly in patients with NSV (7/14) and in contacts of NSU (5/16), though two patients with TV and one in each group with candidiasis, GC, NSGI, and non-VD had a similar association. High counts of $G$ vaginalis were found without anaerobic cocci in three patients (one GC, one NSV, and one contact of NSU). On the other hand, anaerobic Gram-positive cocci were present in high concentrations without $G$ vaginalis in 29 patients, 26 of whom had counts greater than $5.0 \log _{10} \mathrm{cfu} / \mathrm{g}$ of vaginal secretions. In those patients anaerobic Grampositive cocci were associated with other pathogens (seven TV, five Candida, and four GC) and with various clinical conditions (four contacts of NSU, four with NSGI and two with NSV). Patients with Candida (11/17), non-VD (4/7), and TV (8/17) had neither $G$ vaginalis nor anaerobic cocci and are therefore clustered in the lower left-hand corner of the figure.

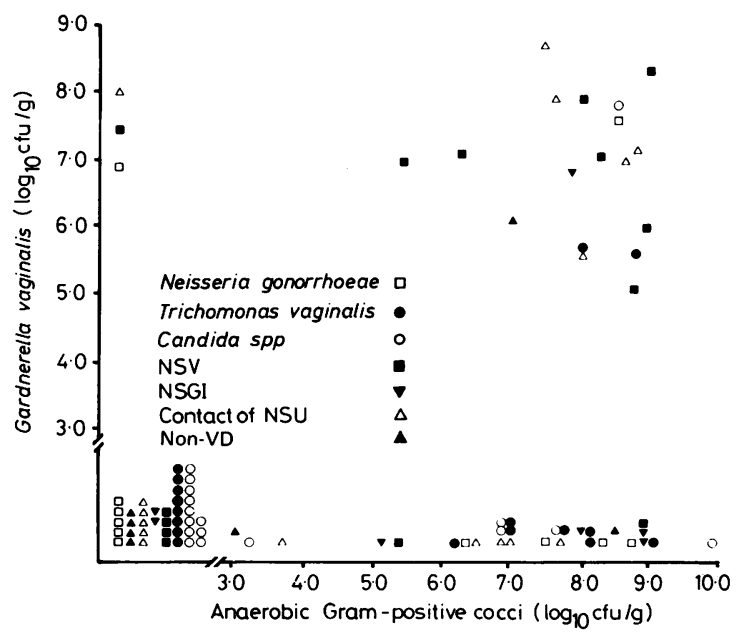

FIG Incidence and concentration of $G$ vaginalis and anaerobic Gram-positive cocci in the vaginal secretions of patients with genital disease

\section{Discussion}

These results showed that $G$ vaginalis was much more commonly isolated and in higher concentrations from patients with non-specific vaginitis than from the other clinical groups. Furthermore, anaerobic bacteria were present in high concentrations in patients with NSV and in association with $G$ vaginalis, but they were not specific to this condition and occurred frequently in other clinical groups and in association with other pathogens. The predominant anaerobic bacteria isolated in association with $G$ vaginalis were peptococci, whereas in contrast to previous reports ${ }^{13}$ we found no correlation between bacteroides species and $G$ vaginalis. Anaerobic Gram-positive cocci were also found together with other pathogens and in particular with $T$ vaginalis. The isolation rate of anaerobic bacteria was similar to that previously reported from asymptomatic women. ${ }^{713}$

The controversy regarding the pathogenicity of $G$ vaginalis still exists. Gardner and Dukes ${ }^{4}$ found that 11 of 15 normal women volunteers who were inoculated with infected vaginal material developed clinical symptoms and had positive culture results for $H(G)$ vaginalis, whereas only one of 13 volunteers inoculated with pure cultures of $H(G)$ vaginalis developed a clinical infection. ${ }^{14}$ This suggests perhaps that in the first experiment other organisms may have also been involved in producing the infection. Pheiffer et $a l^{1}$ and Spiegel $e t a b^{\beta}$ isolated anaerobic bacteria in association with $G$ vaginalis and suggested that certain anaerobes act with $G$ vaginalis in causing vaginitis. ${ }^{13}$ This is further supported by the efficacy of metronidazole treatment in these patients, ${ }^{1-3}$ a drug which is highly active against anaerobic bacteria and only moderately active in vitro against the facultative anaerobe $G$ vaginalis, ${ }^{1-3}$ though the hydroxy metabolite of metronidazole may be more active in vitro against $G$ vaginalis than the parent compound. ${ }^{15}$

The microbiological basis for the association of $G$ vaginitis with anaerobes is not clear. The production of ammonia ${ }^{16}$ and amines ${ }^{1}$ by obligate anaerobes may raise the $\mathrm{pH}$ of the vaginal fluid thereby enabling $G$ vaginalis to thrive. ${ }^{3}$ But this is not specific to $G$ vaginalis; anaerobes are also present with the other pathogens. Whether anaerobic bacteria merely provide a suitable milieu for the growth of pathogens or are actively involved in a mixed infection is not known; nor is it known whether changes in the numbers and types of anaerobic bacteria, in the absence of other vaginal pathogens, can cause symptoms as in our group with non-specific genital disease (NSGI), who may benefit from metronidazole treatment. It seems likely therefore 
that anaerobic bacteria play a significant role in most vaginal infections as they do in other female pelvic infections. ${ }^{17}$

The higher incidence of $G$ vaginalis in our patients who were contacts of NSU suggests that this organism may have been sexually transmitted. Earlier reports by Gardner and Dukes ${ }^{4}$ showed that a high proportion of male sexual partners of women with NSV carried $G$ vaginalis in their urethras, and Pheiffer et al ${ }^{1}$ recovered $G$ vaginalis from $79 \%$ of male sexual partners of infected women. Further prospective work in both partners is, however, needed to determine whether $G$ vaginalis is sexually transmitted.

The isolation rate of $G$ vaginalis from asymptomatic women and from patients with NSV is variable. ${ }^{618}$ This may be due to differences in cultural techniques, ${ }^{6} 1112$ but it is also likely to be due to differences in the criteria used for defining NSV. Hence, it could be argued that $G$ vaginalis vaginitis should be regarded as a separate clinical entity similar to candidosis or trichomoniasis thus enabling the search to continue for other aetiological agents in the culture-negative group.

In conclusion, $G$ vaginalis is predominantly associated with non-specific vaginitis while anaerobic bacteria are not specific to this condition but are also associated with other pathogens and other conditions and may play an important role in the pathogenesis of these infections. Differential treatment regimens with quantitative microbiological analysis are required to assess their relative pathogenicity.

We thank the Joint Research Board of St Bartholomew's Hospital for financial support. We are also indebted to Sister and the nursing staff of the department of genital medicine for their cooperation. Thanks are also due to Miss Lorraine Hall for typing the manuscript.
References

1. Pheiffer TA, Forsyth PS, Durfee MA, Pollock HM, Holmes KK. Non-specific vaginitis; role of Haemophilus vaginalis and treatment with metronidazole. N Engl J Med 1978; 298: 1429-34.

2. Balsdon MJ, Taylor GE, Pead L, Maskell R. Corynebacterium vaginale and vaginitis: a controlled trial of treatment. Lancet 1980; i: $501-4$.

3. Spiegel CA, Amsel R, Eschenbach D, Schoenknecht F, Holmes $\mathrm{KK}$. Anaerobic bacteria in non-specific vaginitis. N Engl JMed 1980; 303:601-7.

4. Gardner HL, Dukes CD. Haemophilus vaginalis vaginitis. Am J Obstet Gynecol 1955;69:962-76.

5. Greenwood JR, Pickett MJ. Transfer of Haemophilus vaginalis Gardner and Dukes to a new genus, Gardnerella: $G$ vaginalis (Gardner and Dukes) comb nov. Int J Syst Bacteriol 1980; 30: 170-8.

6. Dunkelberg WE. Corynebacterium vaginale. Sex Transm Dis 1977; 4:69-75.

7. Levison ME, Corman LC, Carrington ER, Kaye D. Quantitative microflora of the vagina. Am J Obstet Gynecol 1977; 127:80-5

8. Wilks M, Thin RN, Tabaqchali S. Quantitative methods for vaginal flora studies. $J$ Med Microbiol 1982; 15:141-7.

9. Cowan ST. Cowan and Steel's manual for the identification of medical bacteria. 2nd ed. Cambridge: Cambridge University Press, 1974.

10. Holdeman LV, Cato EP, Moore WEC. Anaerobe laboratory manual, 4th ed. Blacksburg, Virginia: Virginia Polytechnic Institute and State University, 1977.

11. Greenwood JR, Pickett MJ. Salient features of Haemophilus vaginalis (Corynebacterium vaginale). J Clin Microbiol 1979;9:200-4.

12. Bailey RK, Voss JL, Smith RF. Factors affecting the isolation and identification of Haemophilus vaginalis (Corynebacterium vaginale).J Clin Microbiol 1979;9:65-71.

13. Bartlett JG, Onderdonk AB, Drude E, et al. Quantitative microbiology of the vaginal flora. J Infect Dis 1977;136:271-7.

14. Criswell BS, Ladwig CL, Gardner HL, Dukes CC. Haemophilus vaginalis: vaginitis by inoculation from culture. Obstet Gynecol 1969; 33: 195-9.

15. Easmon CSF, Ison CA, Kaye CM, Timewell RM, Dawson SG. Pharmacokinetics of metronidazole and its principal metabolites and their activity against Gardnerella vaginalis. $B r$ $J$ Vener Dis 1982; 58:246-9.

16. Chen KCS, Forsyth PS, Buchanan TM, Holmes KK. Amine content of vaginal fluid from untreated and treated patients with non-specific vaginitis. J Clin Invest 1979;63:828-35.

17. Chow AW, Malkasian KL, Marshall JR, Guze LB. The bacteriology of acute pelvic inflammatory disease. Am J Obstet Gynecol 1975; 122:876-9.

18. Bramley HM, Dixon RA, Jones BM. Haemophilus vaginalis in a family planning clinic population. $B r J$ Vener Dis 1981;57:62-6. 